\title{
PNP-Expressing Ovine Atadenovirus FP253
}

National Cancer Institute

\section{Source}

National Cancer Institute. PNP-Expressing Ovine Atadenovirus FP253. NCI Thesaurus.

Code C74074.

An ovine atadenovirus encoding E. coli purine nucleoside phosphorylase (PNP) with prodrug activating activity. Under the control of a prostate-directed promoter, PNPexpressing atadenovirus vaccine FP253 expresses PNP in prostate tissue only after intraprostatic administration; this enzyme catalyzes systemically administered fludarabine prodrug into the active agent, 2-fluoroadenine. Localized prodrug activation provides prostate-targeted chemotherapy, potentially reducing systemic side effects. 